\title{
High-Level Fosfomycin Resistance in Vancomycin-Resistant Enterococcus faecium
}

\author{
Yan Guo, Adam D. Tomich, Christi L. McElheny, \\ Vaughn S. Cooper, Amelia Tait-Kamradt, \\ Minggui Wang, Fupin Hu, Louis B. Rice, \\ Nicolas Sluis-Cremer, Yohei Doi
}

Of 890 vancomycin-resistant Enterococcus faecium isolates obtained by rectal screening from patients in Pittsburgh, Pennsylvania, USA, 4 had MICs $>1,024 \mu \mathrm{g} / \mathrm{mL}$ for fosfomycin. These isolates had a Cys119Asp substitution in the active site of UDP-N-acetylglucosamine enolpyruvyl transferase. This substitution increased the fosfomycin MIC $\geq 4$ fold and rendered this drug inactive in biochemical assays.

$\mathrm{V}$ ancomycin-resistant enterococci can cause nosocomial bacteremia, infective endocarditis, and intraabdominal and urinary tract infections that have limited treatment options. Fosfomycin is an antimicrobial drug that shows a wide spectrum of activity that includes enterococci, staphylococci, and many gram-negative species (1). Fosfomycin inactivates UDP-N-acetylglucosamine enolpyruvyl transferase (MurA) by covalent modification of a highly conserved cysteine residue in the active site of MurA (2). Some bacterial species, such as Borrelia burgdorferi and Mycobacterium tuberculosis, are naturally resistant to fosfomycin because they encode an aspartic acid residue instead of cysteine in the active site of MurA. Furthermore, in Escherichia coli, substitution of this cysteine at position 115 by aspartic acid results in fosfomycin resistance (3).

Fosfomycin has historically shown excellent in vitro activity against vancomycin-resistant enterococci, and therefore might be considered as a treatment option for urinary tract infection caused by this organism (4). However, information regarding the activity of fosfomycin against vancomycin-resistant enterococci in the setting of increasing fosfomycin use is limited (5). We tested vancomycin-resistant enterococcal isolates obtained from rectal screening cultures at the University of Pittsburgh Medical Center (Pittsburgh, PA, USA) during 2012-2016 for fosfomycin resistance.

Author affiliations: University of Pittsburgh Medical Center, Pittsburgh, Pennsylvania, USA (Y. Guo, A.D. Tomich, C.L. McElheny, V.S. Cooper, N. Sluis-Cremer, Y. Doi); Fudan University Huashan Hospital, Shanghai, China (Y. Guo, M. Wang, F. Hu); Brown University, Providence, Rhode Island, USA (A. Tait-Kamradt, L.B. Rice); Fujita Health University, Aichi, Japan (Y. Doi)

DOI: https://doi.org/10.3201/eid2311.171130

\section{The Study}

We tested 890 vancomycin-resistant enterococcal isolates by growth on Mueller-Hinton agar plates containing 100 or $200 \mu \mathrm{g} / \mathrm{mL}$ fosfomycin and $25 \mu \mathrm{g} / \mathrm{mL}$ glucose-6-phosphate (Sigma-Aldrich, St. Louis, MO, USA). Isolates that grew on both selective plates were subjected to determination of MIC by using the agar dilution method on Mueller-Hinton agar plates supplemented with $25 \mu \mathrm{g} / \mathrm{mL}$ glucose-6-phosphate (6).

Of 234 isolates that grew on fosfomycin-containing selective plates, MICs were $32 \mu \mathrm{g} / \mathrm{mL}$ for $10(4.3 \%), 64 \mu \mathrm{g} /$ $\mathrm{mL}$ for $92(39.3 \%), 128 \mu \mathrm{g} / \mathrm{mL}$ for $120(51.3 \%), 256 \mu \mathrm{g} /$ $\mathrm{mL}$ for $7(3.0 \%), 512 \mu \mathrm{g} / \mathrm{mL}$ for $1(0.4 \%)$, and $>1,024 \mu \mathrm{g} /$ $\mathrm{mL}$ for $4(1.7 \%)$. When we used the Clinical and Laboratory Standards Institute breakpoint for urinary tract infections (6), we found that 12 isolates (1.3\%) had MICs $\geq 256 \mu \mathrm{g} / \mathrm{mL}$ and were considered resistant; an additional 120 isolates were considered to have intermediate resistance. The estimated resistance rate of $1.3 \%$ is consistent with that reported in a recent surveillance study conducted in the United States (7). However, the resistance rate would be much higher if we applied the European Committee on Antimicrobial Susceptibility Testing (Växjö, Sweden) breakpoint of $\leq 32 \mu \mathrm{g} / \mathrm{mL}$ for susceptible isolates and $>32 \mu \mathrm{g} / \mathrm{mL}$ for resistant isolates.

The 4 vancomycin-resistant enterococci isolates with MICs $>1,024 \mu \mathrm{g} / \mathrm{mL}$ were Enterococcus faecium. We subjected these isolates and a representative fosfomycinsusceptible E. faecium isolate (kindly provided by L. Harrison) to high-throughput paired-end sequencing by using NextSeq (Illumina, San Diego, CA, USA). We performed de novo assembly by using CLC Genomics Workbench version 10.0 (QIAGEN, Valencia, CA, USA). We deposited assembled genome sequences in GenBank (accession nos. SAMN07274321-5).

The 4 fosfomycin-resistant $E$. faecium isolates belonged to sequence type (ST) $17(\mathrm{n}=2), \mathrm{ST} 18(\mathrm{n}=1)$, and ST233 $(\mathrm{n}=1)$ on the basis of in silico multilocus sequence typing and all had the vanA gene. These STs belong to clonal group 17 , which is a prominent hospital-adapted vancomycin-resistant $E$. faecium clonal lineage associated with outbreaks in healthcare environments $(8)$. None of the isolates had $f o s B$, a transferable bacillithiol S-transferase gene associated with fosfomycin resistance (9). However, murA of the 4 fosfomycin-resistant isolates had a codon change of $\mathrm{TGT}_{\text {Cys1 19 }} \rightarrow \mathrm{GAT}_{\text {Asp 119 }}$ at nucleotide position 355-357, which was not present in the fosfomycin-susceptible control isolate 
or any of the available E. faecium genome sequences and was confirmed by Sanger sequencing (online Technical Appendix Figure, https://wwwnc.cdc.gov/EID/article/23/11/171130-Techapp1.pdf). The murA gene of the 8 remaining fosfomycin-resistant isolates with lower MICs of 256 or 512 $\mu \mathrm{g} / \mathrm{mL}$ did not contain the nonsynonymous mutations corresponding to C119D. Therefore, the C119D substitution was specific to isolates with a fosfomycin MIC $>1,024 \mu \mathrm{g} / \mathrm{mL}$.

We amplified wild-type and mutant (C119D) murA, with their native promoters, by PCR with primers murAF-EcoRI (5'-GAGAGAATTCCATAAAATGAGATGCGGATG-3') and murA-R-BamHI (5'-GAGAGGATCCTTAAGCAATCGTTTGTGCTG-3') (bold indicates restriction endonuclease site sequences) and cloned them into the shuttle vector pTCV-lac (10). We selected E. coli TOP10 transformants by using kanamycin and erythromycin. After confirmation of sequences, we transformed recombinant plasmids into E. coli SM10, subsequently transferred them into E. faecium D344S by conjugation, and performed selection by using kanamycin, fusidic acid, and rifampin. The baseline fosfomycin MIC of the host strain was $128 \mu \mathrm{g} / \mathrm{mL}$. Introduction of pTCV-lac-mur $A^{\mathrm{WT}}$ resulted in a 4-fold increase in the MIC to $512 \mu \mathrm{g} / \mathrm{mL}$, which might be caused by increased expression of WT MurA produced as a result of complementation. Nonetheless, introduction of pTCV-lacmur $^{\text {C119D }}$ yielded a higher MIC of $>1,024 \mu \mathrm{g} / \mathrm{mL}$, which indicated a $\geq 4$-fold increase in the MIC compared with the $m u r A^{\mathrm{WT}}$ control (online Technical Appendix Table). This finding provided phenotypic evidence that C119D MurA is less susceptible to inhibition by fosfomycin.

We determined steady-state Michaelis-Menten parameters for recombinant purified wild-type and C119D MurA (Table; online Technical Appendix). The C119D substitution in MurA increased the mean \pm SD Michaelis constant $\left(K_{\mathrm{m}} 803.2 \pm 180.0 \mu \mathrm{mol} / \mathrm{L}\right)$ for UDP-Nacetylglucosamine compared with the wild-type enzyme $\left(K_{\mathrm{m}} 382.8 \pm 79.5 \mu \mathrm{mol} / \mathrm{L} ; \mathrm{p}=0.02\right)$, but did not affect the catalytic turnover $\left(k_{\text {cat }}\right)$. This increase in $K_{\mathrm{m}}$ resulted in an $\approx 2$-fold decreased catalytic efficiency $\left(k_{\text {cat }} / K_{\mathrm{m}}\right)$ for C119D MurA with respect to UDP-N-acetylglucosamine. In contrast, C119D had no major effect on the kinetic parameters for phosphoenolpyruvate as a substrate (Table). The mean \pm SD $50 \%$ inhibitory concentration of fosfomycin for wild-type MurA was $176.8 \pm 38.3 \mathrm{nmol} / \mathrm{L}$; no inhibition of C119D MurA was observed at concentrations $\leq 100 \mu \mathrm{mol} / \mathrm{L}$ fosfomycin (Figure).

Our finding that high-level fosfomycin resistance in vancomycin-resistant enterococci can be conferred by substitution of the active site cysteine in MurA is consistent with the mode of action of fosfomycin, which covalently and irreversibly binds to the thiol group of this residue. The MurA enzymes in M. tuberculosis and B. burgdorferi are refractory to fosfomycin inhibition and naturally possess aspartic acid at the equivalent position $(11,12)$. Previous site-directed mutagenesis-based studies of E. coli MurA showed that aspartic acid and glutamic acid substitutions, although conferring fosfomycin resistance, had a major effect on catalytic functioning of the enzyme (3). Specifically, the catalytic efficiency of C115D E. coli MurA was reported to be $\geq 10$-fold less than the wild-type enzyme (3).

In our study, the C119D substitution had only minimal effect on vancomycin-resistant enterococci MurA activity. The reason for these differences in kinetic activity is unclear, and additional structure-function studies will be required to elucidate differences between these MurA proteins. Nevertheless, our kinetic data help explain why this substitution was selected in E. faecium, whereas E. coli-producing C115D MurA has not been identified clinically. The nonsynonymous mutations associated with the C119D substitution of MurA were observed only in isolates that had an MIC $>1,024 \mu \mathrm{g} / \mathrm{mL}$ and not in any isolates with lower-level resistance to fosfomycin. Therefore, the mechanisms underlying low-level fosfomycin resistance in enterococci need to be determined.

\section{Conclusions}

In this study, fosfomycin maintained activity against most contemporary vancomycin-resistant enterococci isolates, but we identified high-level resistance caused by substitution of the active site cysteine in MurA, which made it refractory to inhibition by fosfomycin but retained its catalytic activity. Our finding that high-level resistance to fosfomycin might arise through mutations of the target enzyme MurA, accompanied by modest impairment of the catalytic activity, indicates the need for ongoing surveillance activities to ensure its activity against vancomycin-resistant enterococci is maintained. In addition, this finding highlights the potential relevance of aspartic

Table. Michaelis-Menten steady-state kinetic parameters for vancomycin-resistant Enterococcus faecium wild-type and C119D MurA*

\begin{tabular}{|c|c|c|c|c|c|c|c|c|}
\hline \multirow[b]{2}{*}{ Enzyme } & \multicolumn{4}{|c|}{ UNAG ( $p$ value) } & \multicolumn{4}{|c|}{ PEP ( $p$ value) } \\
\hline & $K_{\mathrm{m}}, \mu \mathrm{mol} / \mathrm{L}$ & $\begin{array}{c}V_{\max }, \\
\mu \mathrm{mol} / \mathrm{L} / \mathrm{min}\end{array}$ & $k_{\text {cat }} / \mathrm{min}$ & $\begin{array}{c}k_{\mathrm{cat}} / K_{\mathrm{m}}, \\
\mu \mathrm{mol} / \mathrm{L} / \mathrm{min}\end{array}$ & $K_{\mathrm{m}}, \mu \mathrm{mol} / \mathrm{L}$ & $\begin{array}{c}V_{\max }, \\
\mu \mathrm{mol} / \mathrm{min}\end{array}$ & $k_{\mathrm{cat}} / \mathrm{min}$ & $\begin{array}{c}k_{\text {cat }} / K_{\mathrm{m}} \\
\mu \mathrm{mol} / \mathrm{L} / \mathrm{min}\end{array}$ \\
\hline WT MurA & $382.8 \pm 79.5$ & $13.9 \pm 1.6$ & $138.7 \pm 16.4$ & 0.4 & $229.0 \pm 87.201$ & $29.5 \pm 8.4$ & $294.5 \pm 83.8$ & 1.3 \\
\hline $\begin{array}{l}\text { CD119D } \\
\text { MurA }\end{array}$ & $\begin{array}{c}803.2 \pm 1,780 \\
(0.02)\end{array}$ & $\begin{array}{c}11.9 \pm 2.2 \\
(\mathrm{NS})\end{array}$ & $\begin{array}{c}119.4 \pm 22.2 \\
\text { (NS) }\end{array}$ & 0.2 & $\begin{array}{c}304.6 \pm 35.2 \\
(N S)\end{array}$ & $\begin{array}{c}28.6 \pm 3.2 \\
(\mathrm{NS})\end{array}$ & $\begin{array}{c}285.5 \pm 32.1 \\
(N S)\end{array}$ & 0.9 \\
\hline
\end{tabular}

${ }^{*}$ Values are mean \pm SD for $\geq 3$ independent experiments unless otherwise indicated. Statistical differences between kinetic parameters for vancomycinresistant enterococci WT and C119D MurA were assessed by using a paired $t$-test. MurA, UDP-N-acetylglucosamine enolpyruvyl transferase; NS, not significant; PEP, phosphoenolpyruvate; UNAG, UDP-N-acetylglucosamine; WT, wild type. 

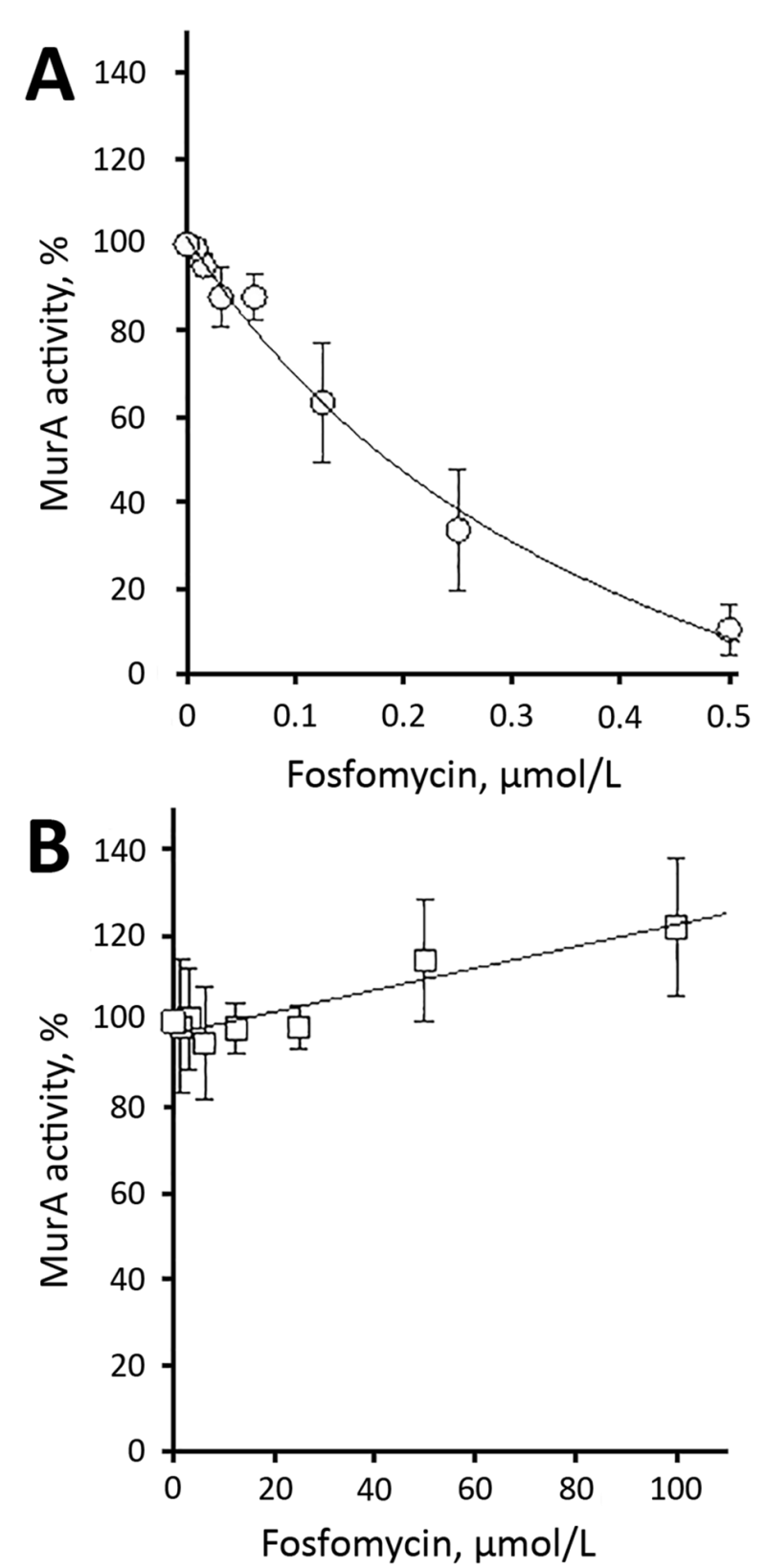

Figure. Inhibition of recombinant purified vancomycin-resistant Enterococcus faecium wild-type (A) and C119D (B) MurA by fosfomycin. The $50 \%$ inhibitory concentration was $176.8 \pm 38.3$ $\mathrm{nmol} / \mathrm{L}$ for wild-type MurA and $>100 \mu \mathrm{mol} / \mathrm{L}$ for C119D MurA. Error bars indicate mean \pm SD of $\geq 3$ independent experiments. MurA, UDP-N-acetylglucosamine enolpyruvyl transferase.

acid-substituted, catalytically active MurA enzymes as a target for inhibitor development.

\section{Acknowledgment}

We thank Lee Harrison for providing vancomycin-resistant

E. faecium isolates used in this study.

Y.D. was supported by grants from the National Institutes of Health (R01AI104895 and R21AI123747).
Dr. Guo is a visiting researcher in the Division of Infectious Diseases, University of Pittsburgh Medical Center, Pittsburgh, PA. Her research interests include mechanisms of multidrug resistance in gram-positive bacteria.

\section{References}

1. Sastry S, Doi Y. Fosfomycin: resurgence of an old companion. J Infect Chemother. 2016;22:273-80. http://dx.doi.org/10.1016/ j.jiac.2016.01.010

2. Eschenburg S, Priestman M, Schönbrunn E. Evidence that the fosfomycin target Cys115 in UDP-N-acetylglucosamine enolpyruvyl transferase (MurA) is essential for product release. J Biol Chem. 2005;280:3757-63. http://dx.doi.org/10.1074/jbc.M411325200

3. Kim DH, Lees WJ, Kempsell KE, Lane WS, Duncan K, Walsh CT. Characterization of a Cys115 to Asp substitution in the Escherichia coli cell wall biosynthetic enzyme UDP-GlcNAc enolpyruvyl transferase (MurA) that confers resistance to inactivation by the antibiotic fosfomycin. Biochemistry. 1996;35:4923-8. http://dx.doi.org/10.1021/bi952937w

4. Sastry S, Clarke LG, Alrowais H, Querry AM, Shutt KA, Doi Y. Clinical appraisal of fosfomycin in the era of antimicrobial resistance. Antimicrob Agents Chemother. 2015;59:7355-61. http://dx.doi.org/10.1128/AAC.01071-15

5. Falagas ME, Roussos N, Gkegkes ID, Rafailidis PI, Karageorgopoulos DE. Fosfomycin for the treatment of infections caused by gram-positive cocci with advanced antimicrobial drug resistance: a review of microbiological, animal and clinical studies. Expert Opin Investig Drugs. 2009;18:921-44. http://dx.doi.org/10.1517/13543780902967624

6. Clinical and Laboratory Standards Institute. Performance standards for antimicrobial susceptibility testing, 27th edition (M100-S27). Wayne (PA): The Institute; 2017.

7. Keepers TR, Gomez M, Celeri C, Krause KM, Biek D, Critchley I. Fosfomycin and comparator activity against select Enterobacteriaceae, Pseudomonas, and Enterococcus urinary tract infection isolates from the United States in 2012. Infect Dis Ther. 2017;6:233-43. http://dx.doi.org/10.1007/s40121-017-0150-5

8. Cattoir V, Leclercq R. Twenty-five years of shared life with vancomycin-resistant enterococci: is it time to divorce? J Antimicrob Chemother. 2013;68:731-42. http://dx.doi.org/ 10.1093/jac/dks469

9. Xu X, Chen C, Lin D, Guo Q, Hu F, Zhu D, et al. The fosfomycin resistance gene $f o s B 3$ is located on a transferable, extrachromosomal circular intermediate in clinical Enterococcus faecium isolates. PLoS One. 2013;8:e78106. http://dx.doi.org/10.1371/journal.pone.0078106

10. Poyart C, Trieu-Cuot P. A broad-host-range mobilizable shuttle vector for the construction of transcriptional fusions to beta-galactosidase in gram-positive bacteria. FEMS Microbiol Lett. 1997;156:193-8. http://dx.doi.org/10.1016/ S0378-1097(97)00423-0

11. De Smet KA, Kempsell KE, Gallagher A, Duncan K, Young DB. Alteration of a single amino acid residue reverses fosfomycin resistance of recombinant MurA from Mycobacterium tuberculosis. Microbiology. 1999;145:3177-84. http://dx.doi.org/ 10.1099/00221287-145-11-3177

12. Jiang S, Gilpin ME, Attia M, Ting YL, Berti PJ. Lyme disease enolpyruvyl-UDP-GlcNAc synthase: fosfomycin-resistant MurA from Borrelia burgdorferi, a fosfomycin-sensitive mutant, and the catalytic role of the active site Asp. Biochemistry. 2011;50:2205-12. http://dx.doi.org/10.1021/bi1017842

Address for correspondence: Yohei Doi, Division of Infectious Diseases, University of Pittsburgh Medical Center, S829 Scaife Hall, 3550 Terrace St, Pittsburgh, PA 15261, USA; email: yod4@pitt.edu 